\title{
Receitas bruta e líquida parcial e custo de dietas contendo polpa cítrica para suínos abatidos com $130 \mathrm{~kg}$ de peso
}

\author{
[Gross and partial net incomes and feeding cost of diets containing citrus pulp for pigs \\ slaughtered with $130 \mathrm{~kg}$ of weight] \\ P.H. Watanabe ${ }^{1}$, M.C. Thomaz ${ }^{2 *}$, M.I.E.G. Martins $^{2}$, U.S. Ruiz ${ }^{1}$, A.L. Fraga ${ }^{3}$, V.M. Santos ${ }^{1}$,
L.A.F. Pascoal ${ }^{1}$, S.Z. Silva \\ ${ }^{1}$ Aluno de pós-graduação - FCAV-UNESP - Jaboticabal, SP \\ ${ }^{2}$ Faculdade de Ciências Agrárias e Veterinárias - UNESP \\ Via de acesso Prof. Paulo D. Castellane, $\mathrm{s} / \mathrm{n}$ \\ 14884-900 - Jaboticabal, SP \\ ${ }^{3}$ In memorian \\ ${ }^{4}$ Aluno de graduação - FCAV-UNESP - Jaboticabal, SP
}

\section{RESUMO}

Avaliou-se o custo de inclusão da polpa cítrica em programa de restrição alimentar qualitativa, utilizando dados de desempenho de 36 suínos da linhagem Topigs, dos 83,7 $75,1 \mathrm{~kg}$ aos $129,8 \pm 1,9 \mathrm{~kg}$ de peso, alimentados com dietas contendo porcentagens crescentes $(0,10,20$ e $30 \%)$ de polpa cítrica. Os animais foram abatidos aos $130 \mathrm{~kg}$ e dos valores $(\mathrm{R} \$)$ da carcaça foram descontados o valor de compra dos animais e o custo com alimentação, de acordo com cada tratamento. Não houve efeito $(P>0,05)$ da inclusão da polpa cítrica sobre o custo com ração e receita bruta, porém houve efeito linear negativo $(\mathrm{P}<0,05)$ sobre o rendimento líquido parcial com o aumento da participação da polpa cítrica nas dietas. A queda no rendimento líquido parcial foi causada pelo menor peso da carcaça obtida de animais alimentados com porcentagem mais elevada de polpa cítrica. Considerando a evolução dos preços do milho, do farelo de soja e do suíno entre junho de 2005 e maio de 2006, foram determinados 12 diferentes cenários para o rendimento líquido parcial. Em todos esses cenários, foi observada redução linear da receita líquida parcial em função da inclusão da polpa cítrica, mostrando que esse ingrediente não foi eficiente em promover melhora no rendimento $(\mathrm{R} \$)$ ao produtor.

Palavras-chave: suíno, custo, receita bruta, receita líquida parcial, restrição alimentar

\begin{abstract}
The cost of inclusion of citrus pulp was evaluated in a qualitative feed restriction program using performance data of 36 pigs of Topigs lineage (from $83.7 \pm 5.1 \mathrm{~kg}$ to $129.8 \pm 1.9 \mathrm{~kg}$ ) fed with crescent levels of citrus pulp $(0,10,20$, and $30 \%)$. The animals were slaughtered when they reached $130 \mathrm{~kg}$. The value paid for animal and its feeding cost were discounted from the carcass value (R\$), according to each treatment. No effect $(P>0.05)$ of the inclusion of citrus pulp on ration cost and gross income was observed. A negative linear effect $(<0.05)$ on partial net income with the increasing participation of the citrus pulp in diets was found. The decreasing trend in the partial net income was caused by the reduction on carcass weight of animals fed on crescent levels of citrus pulp. Considering the increase on corn, soybean, and swine prices from June 2005 to May 2006, 12 different sceneries were determined for partial net income analysis. In all situations, linear reductions on partial net income were observed as a function of citrus pulp inclusion, evidencing that the ingredient was not efficient in promoting profits for producers.
\end{abstract}

Keywords: swine, cost, feed restriction, gross income, partial net income

Recebido em 28 de maio de 2008

Aceito em 15 de dezembro de 2009

*Autor para correspondência (corresponding author)

E-mail: thomaz@fcav.unesp.br 


\section{INTRODUÇÃO}

Na suinocultura brasileira, o peso médio de abate dos suínos situa-se em torno de $100 \mathrm{~kg}$, com, aproximadamente, seis meses de idade (Santos Filho et al., 2001). Entretanto, verifica-se tendência para aumento do peso de abate no Brasil, por permitir à indústria de abate e processamento o desenvolvimento de novos produtos e a otimização do uso da linha de abate.

Todavia, levar os animais até o abate com mais de $100 \mathrm{~kg}$ de peso, sem manejo nutricional adequado, pode resultar em alto consumo de ração, sendo o excedente energético convertido em gordura (Noblet, 1996). Portanto, para justificar a adoção de manejo nutricional diferenciado, como a restrição alimentar, os custos com alimentação bem como as receitas envolvidas devem ser avaliados. De acordo com Penz Júnior e Viola (1998), a alimentação corresponde a $65 \%$ dos custos de produção, e as dietas de terminação representam entre 50 e $55 \%$ dos custos com alimentação.

A restrição do consumo energético, seja por meio do controle de consumo ou da diluição energética da ração, é uma ferramenta importante na alimentação de suínos com peso acima de $100 \mathrm{~kg}$, quando se procura obter melhoras em características de carcaça (Viola et al., 1998). De acordo com Galassi et al. (2004), para a produção de suínos com peso de abate próximo de $160 \mathrm{~kg}$ e reduzido percentual de gordura na carcaça, é necessário restringir o consumo de ração e de energia, limitando o uso de ingredientes de alto teor energético como o milho.

Silva et al. (2006) afirmaram que os subprodutos originados de processamento industrial alimentar têm potencial de uso e, na maioria dos casos, com redução nos custos de produção.

Como o Brasil é o maior produtor de laranja e mais de $70 \%$ dessa produção é destinada à extração de suco (Subprodutos..., 2006), há grande disponibilidade de resíduos, como a polpa cítrica, que podem ser utilizados na alimentação animal. Embora seja utilizada na alimentação de ruminantes, a inclusão de polpa cítrica em dietas para suínos ainda é pouco estudada.
Considerando sua composição em fibras e a tendência à redução do consumo quando incluída em certas concentrações na dieta (Domínguez, 1995), a polpa cítrica pode proporcionar restrição alimentar qualitativa para suínos. Assim, o objetivo deste trabalho foi analisar o custo da inclusão de porcentagens crescentes de polpa cítrica em programas de restrição alimentar qualitativa e avaliar as receitas bruta e líquida parcial de suínos abatidos com $130 \mathrm{~kg}$.

\section{MATERIAL E MÉTODOS}

Os custos da inclusão de polpa cítrica na dieta de suínos submetidos à restrição alimentar qualitativa basearam-se nos dados do ensaio de desempenho de 36 machos castrados, alojados em baias individuais, no período de março a maio de 2006.

Os animais, distribuídos em quatro tratamentos, em delineamento em blocos ao acaso, com nove repetições por tratamento, apresentavam peso médio de $83,7 \pm 5,1 \mathrm{~kg}$. As dietas foram formuladas para atender às exigências indicadas pelo software do NRC (Nutrient..., 1998), considerando a concentração energética da dietacontrole de $3365 \mathrm{kcal} \mathrm{ED} / \mathrm{kg}$ de ração para machos castrados, com peso vivo de $105 \mathrm{~kg}$, alto potencial genético e temperatura média no período experimental de $24^{\circ} \mathrm{C}$ (Tab. 1). Para a formulação das dietas, foram utilizados os valores de energia digestível e cálcio disponível da polpa cítrica obtidos em ensaio anterior, $2496,04 \mathrm{kcal} / \mathrm{kg}$ e $0,009 \%$.

Os tratamentos experimentais foram: dietacontrole - composta principalmente por milho e farelo de soja; dieta Pc10 - formulada para atingir os mesmos níveis de lisina digestível, cálcio e fósforo disponível da dieta-controle, mas com a inclusão de $10 \%$ de polpa cítrica; dieta Pc20 - formulada para atingir os mesmos níveis de lisina digestível, cálcio e fósforo disponível da dieta-controle, mas com a inclusão de $20 \%$ de polpa cítrica; dieta Pc30 - formulada para atingir os mesmos níveis de lisina digestível, cálcio e fósforo disponíveis da dieta-controle, mas com a inclusão de $30 \%$ de polpa cítrica.

Os animais receberam ração e água à vontade durante todo o ensaio, sendo as sobras recolhidas e pesadas diariamente. $\mathrm{O}$ peso foi registrado semanalmente. Por meio da soma dos consumos, 
obteve-se o consumo total de ração durante o período experimental. Quando atingiam o peso final estabelecido de $130 \mathrm{~kg}$, os animais foram retirados do ensaio e abatidos, e as carcaças serradas longitudinalmente. Nas meias-carcaças direitas, foram mensurados a espessura de toucinho (ET), a profundidade de lombo (PL) e o peso da carcaça quente (PCQ), utilizados para a obtenção da porcentagem de carne magra $(\% \mathrm{CM})$, conforme a equação proposta por Guidoni (2000).

Com os valores de \%CM e PCQ foi determinado o índice de bonificação (IB), que é um fator de correção do valor da carcaça, expresso em porcentagem, conforme a equação indicada por Fávero et al. (1997).

Foi determinado o valor final, em reais, recebido pelos suínos (R\$ suíno $130 \mathrm{~kg}$ ), dentro do sistema de tipificação, com base no IB, PCQ e preço do suíno vivo em maio de 2006, conforme a equação descrita por Fávero et al. (1997):

$\mathrm{R} \$$ suíno $130 \mathrm{~kg}=[\mathrm{IB} \times$ (preço do quilograma do suíno vivo / 0,7145)] x PCQ

Tabela 1. Composições centesimal, química e energética das dietas experimentais utilizadas para suínos

\begin{tabular}{|c|c|c|c|c|}
\hline Ingrediente, $\%$ & Controle & Pc10 & Pc20 & $\mathrm{Pc} 30$ \\
\hline Milho & 81,78 & 71,01 & 60,24 & 49,43 \\
\hline Farelo de soja & 16,40 & 17,17 & 17,94 & 18,75 \\
\hline Polpa cítrica & 0,00 & 10,00 & 20,00 & 30,00 \\
\hline Calcário calcítico & 0,58 & 0,58 & 0,57 & 0,57 \\
\hline Fosfato bicálcico & 0,64 & 0,64 & 0,65 & 0,65 \\
\hline Sal comum & 0,30 & 0,30 & 0,30 & 0,30 \\
\hline Suplemento vit $+\min ^{1}$ & 0,30 & 0,30 & 0,30 & 0,30 \\
\hline Total & 100,00 & 100,00 & 100,00 & 100,00 \\
\hline \multicolumn{5}{|l|}{ Composição calculada $^{2}$} \\
\hline Energia digestível, kcal/kg & 3391 & 3294 & 3197 & 3100 \\
\hline Proteína bruta, $\%$ & 14,87 & 14,28 & 14,37 & 14,48 \\
\hline FDN, $\%^{3}$ & 11,88 & 12,61 & 13,33 & 14,06 \\
\hline FDA, $\%^{3}$ & 4,23 & 5,35 & 6,46 & 7,57 \\
\hline FSDN, $\%^{3}$ & 7,41 & 10,95 & 14,63 & 18,04 \\
\hline Amido, $\%$ & 54,91 & 48,34 & 41,76 & 35,17 \\
\hline Lisina dig., $\%$ & 0,58 & 0,58 & 0,58 & 0,58 \\
\hline Metionina + cistina dig., $\%$ & 0,46 & 0,43 & 0,41 & 0,38 \\
\hline Cálcio, \% & 0,44 & 0,44 & 0,44 & 0,44 \\
\hline Fósforo disp., $\%$ & 0,18 & 0,18 & 0,17 & 0,17 \\
\hline
\end{tabular}

Pc10: dieta com inclusão de 10\% de polpa cítrica; Pc20: dieta com inclusão de 20\% de polpa cítrica; Pc30: dieta com inclusão de $30 \%$ de polpa cítrica.

${ }^{1}$ Suplemento vitamínico - quantidade kg/produto: vit.A: 2.500.000UI; vit.D3: 500.000UI; biotina: 50mg; colina: 50mg; niacina: $10000 \mathrm{mg}$; pantotenato de cálcio: 3000mg; vit.B12: 7mg; vit.B2: $1800 \mathrm{mg}$; vit.E: 7500mg; vit.K3: $1000 \mathrm{mg}$. Suplemento mineral - quantidade kg/produto: ferro: $40.000 \mathrm{mg}$; cobre: $35.000 \mathrm{mg}$; manganês: $20.000 \mathrm{mg}$; zinco: $40.000 \mathrm{mg}$; cobalto: $360 \mathrm{mg}$; iodo: $840 \mathrm{mg}$; selênio: $120 \mathrm{mg}$.

${ }^{2}$ Valores nutricionais dos ingredientes propostos por Rostagno et al. (2005).

${ }^{3}$ FDN: Fibra em detergente neutro; FDA: fibra em detergente ácido; FSDN: fibra solúvel em detergente neutro - \% obtidas por meio de análise laboratorial. 
Para calcular o custo de cada dieta experimental, foram utilizados como base os preços dos ingredientes praticados em Jaboticabal, em março de 2006, início do período experimental. O custo com ração foi determinado com base no consumo total de cada animal durante o período experimental e do custo de cada dieta.

A partir do peso inicial de $83,7 \pm 5,1 \mathrm{~kg}$ e do preço do quilograma do suíno vivo em março de 2006, foi obtido o valor inicial, em reais ( $\mathrm{R} \$$ suíno $83 \mathrm{~kg}$ ), dos animais no início do ensaio. Com os valores inicial e final e com o custo da ração, foram calculadas as receitas bruta e líquida parcial, referentes àquela data, em reais $(\mathrm{R} \$)$, conforme as equações:

Receita bruta $=\mathrm{R} \$$ suíno $130 \mathrm{~kg}-\mathrm{R} \$$ suíno $83 \mathrm{~kg}$

Receita líquida parcial $=$ receita bruta - custo com ração
Foram realizadas simulações de receita líquida parcial, considerando os preços mensais do quilograma do suíno, milho e farelo de soja ao longo do período de junho de 2005 a maio de 2006 (Tab. 2), fixando os preços dos demais ingredientes das dietas (Tab. 3), obtendo-se valores de receita líquida parcial para cada mês, dentro do período citado.

Os custos com ração e as receitas bruta e líquida parcial referentes ao mês de maio de 2006, e a receita líquida parcial de cada mês, no período de junho de 2005 a maio de 2006, após serem analisados quanto à homogeneidade de variâncias (teste Levene a 5\%) entre os tratamentos, foram submetidos à análise de variância, utilizando-se o pacote PROC GLM do programa estatístico SAS/1998.

Tabela 2. Valores $(\mathrm{R} \$ / \mathrm{kg})$ de milho, farelo de soja e suíno, entre junho de 2005 e maio de 2006

\begin{tabular}{lccc}
\hline Mês/ano & Milho & Farelo de soja & Suíno \\
\hline Junho/2005 & 0,31 & 0,54 & 2,13 \\
Julho/2005 & 0,31 & 0,54 & 2,33 \\
Agosto/2005 & 0,30 & 0,53 & 2,42 \\
Setembro/2005 & 0,30 & 0,52 & 2,54 \\
Outubro/2005 & 0,29 & 0,49 & 2,57 \\
Novembro/2005 & 0,27 & 0,49 & 2,38 \\
Dezembro/2005 & 0,27 & 0,52 & 2,32 \\
Janeiro/2006 & 0,27 & 0,53 & 1,79 \\
Fevereiro/2006 & 0,27 & 0,48 & 1,96 \\
Março/2006 & 0,23 & 0,41 & 1,67 \\
Abril/2006 & 0,23 & 0,39 & 1,63 \\
Maio/2006 & 0,24 & 0,43 & 1,51 \\
\hline
\end{tabular}

Tabela 3. Valores $(\mathrm{R} \$ / \mathrm{kg})$ dos demais ingredientes das dietas experimentais

\begin{tabular}{cccccc} 
& Polpa cítrica & Calcário calcítico & Fosfato bicálcico & Sal comum & $\begin{array}{c}\text { Suplemento } \\
\text { vit+min }\end{array}$ \\
\hline $\mathrm{R} \$ / \mathrm{kg}$ & 0,20 & 0,13 & 1,30 & 0,25 & 4,90 \\
\hline
\end{tabular}

\section{RESULTADOS E DISCUSSÃO}

$\mathrm{Na}$ Tab. 4, encontram-se os valores médios de espessura do toucinho (ET), profundidade do lombo (PL), peso da carcaça quente (PCQ), porcentagem de carne magra $(\% \mathrm{CM})$ e índice de bonificação
(IB), segundo a porcentagem de inclusão de polpa cítrica e, na Fig. 1, encontram-se as equações de regressão referentes ao efeito linear da inclusão da polpa cítrica sobre o peso da carcaça quente $\mathrm{e}$ profundidade do lombo de suínos. 
Tabela 4. Valores médios e coeficientes de variação (CV) da espessura do toucinho (ET), profundidade do lombo (PL), peso da carcaça quente (PCQ), porcentagem de carne magra $(\% \mathrm{CM})$ e índice de bonificação (IB) de acordo com a proporção de inclusão de polpa cítrica à dieta de suínos

\begin{tabular}{lcccccccc}
\hline \multirow{2}{*}{ Característica } & \multicolumn{9}{c}{ Polpa cítrica, \% } & \multirow{2}{*}{ CV, \% } & Efeito & \multirow{2}{*}{ P } \\
\cline { 2 - 5 } ET, mm & 0 & 10 & 20 & 30 & & & \\
PL, mm & 15,9 & 15,9 & 14,9 & 16,2 & 14,77 & - & $>0,1$ \\
PCQ, kg & 77,4 & 78,9 & 72,2 & 68,9 & 8,61 & Linear & 0,0029 \\
\%CM & 99,2 & 97,3 & 95,0 & 93,6 & 1,31 & Linear & $<0,0001$ \\
IB & 59,8 & 59,9 & 60,0 & 58,8 & 2,90 & - & $>0,1$ \\
\hline
\end{tabular}
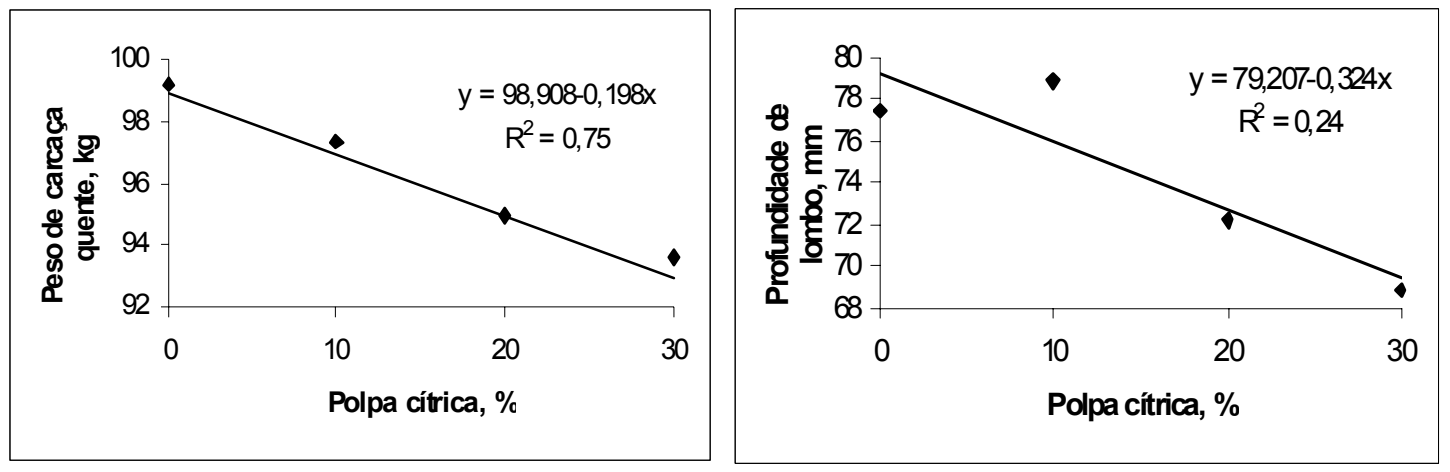

Figura 1. Peso da carcaça quente e profundidade do lombo e equação de regressão segundo a porcentagem de inclusão da polpa cítrica à dieta de suínos

A inclusão de polpa cítrica nas dietas não reduziu a ET e, desse modo, não melhorou a qualidade da carcaça dos suínos abatidos aos $130 \mathrm{~kg}$. Foi observada redução linear $(\mathrm{P}<0,05)$ na $\mathrm{PL}$ e no PCQ com o aumento da porcentagem de polpa cítrica, porém tal decréscimo não foi suficiente para afetar a \%CM e o IB.

$\mathrm{Na}$ Tab. 5, encontram-se os dados referentes aos custos do $\mathrm{kg}$ das rações, custos com ração, receitas bruta e líquida parcial, em função da porcentagem de inclusão da polpa cítrica, referentes ao mês de maio de 2006.

A inclusão de polpa cítrica à dieta não resultou em redução do custo com ração e receita bruta. Para a receita líquida parcial, foi observado efeito linear negativo $(\mathrm{P}=0,0025)$ em razão da proporção de inclusão da polpa (Fig. 2).

Tabela 5. Valores médios e coeficientes de variação (CV) do custo de alimentação e das receitas bruta e líquida parcial obtidas por suíno, dos 83 aos $130 \mathrm{~kg}$, de acordo com a proporção de inclusão de polpa cítrica à dieta de suínos

\begin{tabular}{|c|c|c|c|c|c|c|c|}
\hline \multirow{2}{*}{ Valor, R\$ } & \multicolumn{4}{|c|}{ Polpa cítrica, \% } & \multirow{2}{*}{$\mathrm{CV}, \%$} & \multirow{2}{*}{ Regressão } & \multirow{2}{*}{$\mathrm{P}$} \\
\hline & 0 & 10 & 20 & 30 & & & \\
\hline Custo do kg da ração & 0,291 & 0,288 & 0,286 & 0,283 & - & - & - \\
\hline Custo com ração & 46,73 & 45,72 & 44,90 & 48,34 & 16,41 & - & 0,79 \\
\hline Receita bruta & 101,13 & 98,61 & 92,42 & 88,26 & 12,67 & - & 0,12 \\
\hline Receita líquida parcial & 54,40 & 52,89 & 47,52 & 39,92 & 16,58 & Linear & 0,0025 \\
\hline
\end{tabular}




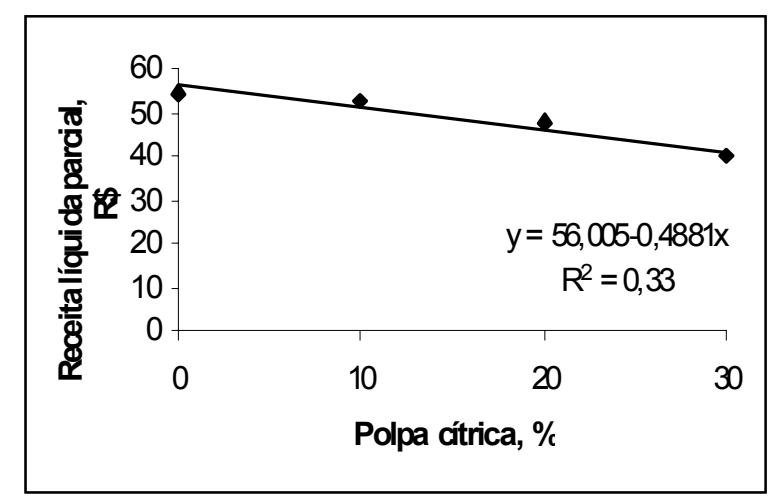

Figura 2. Receita líquida parcial referente ao mês de maio de 2006, em função da porcentagem de inclusão de polpa cítrica à dieta de suínos.

Fraga (2005), ao avaliar o efeito da restrição alimentar qualitativa por meio da inclusão de casca de arroz, encontrou aumento da receita bruta $(\mathrm{P}<0,05)$ em função da restrição alimentar devido à melhora do índice de bonificação. Entretanto, como a receita líquida parcial depende do valor da venda do suíno e também do valor dos ingredientes das dietas, esse autor não observou maior receita com maior restrição alimentar. Assim, os custos dos ingredientes a serem utilizados podem ser limitantes para a adoção da restrição alimentar qualitativa.

$\mathrm{Na}$ Tab. 6, encontram-se os dados referentes à receita líquida parcial em função da porcentagem de inclusão da polpa cítrica, no período de junho de 2005 a maio de 2006.

Tabela 6. Receita líquida parcial de suínos, dos $83,7 \pm 5,1$ aos $129,8 \pm 1,9 \mathrm{~kg}$ de peso, sob diferentes cenários de preços de milho, farelo de soja e suíno ${ }^{1}$, de acordo com a inclusão de polpa cítrica na dieta de suínos

\begin{tabular}{lccccc}
\hline \multirow{2}{*}{ Mês/ano } & \multicolumn{4}{c}{ Polpa cítrica, \% } & \multicolumn{2}{c}{ Valor de P } \\
\cline { 2 - 5 } & 0 & 10 & 20 & 30 & Efeito linear \\
\hline Junho/2005 & $74,53 \pm 4,16$ & $73,26 \pm 4,50$ & $66,53 \pm 2,80$ & $57,73 \pm 4,23$ & 0,0025 \\
Julho/2005 & $143,84 \pm 4,13$ & $142,23 \pm 3,88$ & $134,79 \pm 2,90$ & $124,40 \pm 4,21$ & 0,0004 \\
Agosto/2005 & $150,55 \pm 4,39$ & $148,59 \pm 4,29$ & $140,61 \pm 3,03$ & $129,91 \pm 4,29$ & 0,0004 \\
Setembro/2005 & $153,29 \pm 4,76$ & $151,13 \pm 4,86$ & $142,63 \pm 3,22$ & $131,73 \pm 4,46$ & 0,0006 \\
Outubro/2005 & $152,15 \pm 4,93$ & $149,83 \pm 5,17$ & $141,09 \pm 3,29$ & $130,24 \pm 4,99$ & 0,0007 \\
Novembro/2005 & $114,98 \pm 4,83$ & $112,51 \pm 5,84$ & $104,04 \pm 3,16$ & $93,98 \pm 4,35$ & 0,0009 \\
Dezembro/2005 & $101,52 \pm 4,73$ & $99,17 \pm 5,25$ & $90,95 \pm 3,09$ & $81,09 \pm 4,35$ & 0,0011 \\
Janeiro/2006 & $32,37 \pm 3,57$ & $30,88 \pm 4,08$ & $24,74 \pm 2,44$ & $16,91 \pm 3,78$ & 0,0025 \\
Fevereiro/2006 & $66,93 \pm 3,97$ & $65,10 \pm 4,39$ & $58,27 \pm 2,62$ & $49,74 \pm 3,89$ & 0,0013 \\
Março/2006 & $71,49 \pm 3,17$ & $69,55 \pm 3,27$ & $63,38 \pm 2,13$ & $55,22 \pm 3,29$ & 0,0002 \\
Abril/2006 & $51,42 \pm 3,29$ & $49,54 \pm 3,60$ & $43,50 \pm 2,17$ & $35,86 \pm 3,32$ & 0,0006 \\
Maio/2006 & $54,40 \pm 2,77$ & $52,89 \pm 2,76$ & $47,51 \pm 1,94$ & $39,92 \pm 3,15$ & 0,0002 \\
\hline
\end{tabular}

${ }^{1}$ média \pm erro-padrão da média.

Ao longo dos 12 cenários mensais analisados, foi observada redução linear da receita líquida parcial $(\mathrm{P}<0,05)$, em função da inclusão da polpa cítrica, independente das cotações do milho, farelo de soja e suíno, observadas ao longo do ano. De acordo com Fraga (2005), o preço do quilograma do milho é o fator mais relacionado com a lucratividade da restrição alimentar qualitativa, sendo maior a viabilidade econômica de sua utilização quanto maior a diferença entre 
o preço do milho e do ingrediente alternativo. No presente experimento, a maior diferença observada entre os preços do milho e da polpa cítrica foi de $\mathrm{R} \$ 0,11$, valor insuficiente para equilibrar o custo da alimentação.

Pesquisas avaliando custos de produção de suínos na fase de terminação são escassas (Bastos et al., 2002, 2006), mas importantes, visto que podem representar situações da produção comercial de larga escala (Silva et al., 2008). Para a adoção de restrição alimentar qualitativa, para suínos abatidos com peso acima de $120 \mathrm{~kg}$, deve ser avaliada a disponibilidade do subproduto a custo reduzido, bem como a melhora nas características da carcaça. No presente trabalho, a polpa cítrica em programas de restrição alimentar qualitativa não foi eficiente em promover a melhora na qualidade da carcaça, e até reduziu o seu peso, não resultando em melhores índices de bonificação. Soma-se, ainda, o fato de que o custo da polpa cítrica foi relativamente alto no momento de aquisição, fato agravado com o aumento do número de dias necessários para os animais atingirem $130 \mathrm{~kg}$, quando a inclusão foi de $30 \%$.

Fraga (2005) ponderou que, em programas de restrição alimentar qualitativa, quanto maior a relação entre os preços do milho e do ingrediente alternativo, menor será o custo para se atingir o peso de abate acima de $120 \mathrm{~kg}$, ressaltando ainda a importância em utilizar resíduos da indústria alimentícia de baixo valor comercial.

\section{CONCLUSÕES}

Em função do preço da polpa cítrica e da diminuição da receita líquida parcial com o aumento da porcentagem desse ingrediente na dieta, não se justifica sua utilização em programas de restrição alimentar qualitativa.

\section{REFERÊNCIAS BIBLIOGRÁFICAS}

BASTOS, A.O.; LANDELL FILHO, L.C.; PASSIPIERI, M. et al. Diferentes níveis de grão de milheto (Pannisetum glaucum (L.) R. Brown) na alimentação de suínos. Rev. Bras. Zootec., v.31, p.1753-1760, 2002.

BASTOS, A.O.; MOREIRA, I.; FURLAN, A.C. et al. Efeitos da inclusão de níveis crescentes de milheto (Pannisetum glaucum (L.) R. Brown) grão na alimentação de suínos em crescimento e terminação. Rev. Bras. Zootec., v.35, p.98-103, 2006.

DOMÍNGUEZ, P.L. Pulpa de cítricos en la alimentación de cerdos. Rev. Comput. Prod. Porc., v.2, p.101-105, 1995.

FÁVERO, J.A.; GUIDONI, A.L.; BELLAVER, C. Predição do índice de valorização de carcaças suínas em função do peso e do percentual de carne. In: CONGRESSO DA ASSOCIAÇÃO BRASILEIRA DE VETERINÁRIOS ESPECIALISTAS EM SUÍNOS, 8., 1997, Concórdia. Anais... Concórdia: Embrapa/CNPSA, 1997. p.405-406.

FRAGA, A.L. Restrição alimentar qualitativa para suínos com elevado peso de abate. 2005. 94f. Tese (Doutorado) - Faculdade de Ciências Agrárias e Veterinárias, Universidade Estadual Paulista, Jaboticabal.

GALASSI, G.; CROVETTO, G.M.; RAPETTI, L. et al. Energy and nitrogen balance in heavy pigs fed different fibre sources. Livest. Prod. Sci., v.85, p.253-262, 2004.

GUIDONI, A.L. Melhoria dos processos para tipificação de carcaças suínas no Brasil. In: CONFERÊNCIA INTERNACIONAL VIRTUAL SOBRE QUALIDADE DE CARNE SUÍNA, 1., 2000, Concórdia. Anais eletrônicos... Concórdia: Embrapa/CNPSA, 2000. Disponível em: <http://www.cnpsa.embrapa.br/pork/> Acessado em: 12 fev. 2006.

NOBLET, J. Net energy for growth in pigs: application to low protein, amino acid supplemented diets. In: PORK INDUSTRY CONFERENCE, 1996, Urbana. Proceedings... Urbana: University of Illinois, 1996. p.15-25.

NUTRIENT requirements of swine. 10.ed. Washington: National Academic of Sciences, 1998. 190p.

PENZ JÚNIOR, A.M.; VIOLA, E.S. Nutrição. In: SOBESTIANSKY, J.; WENTZ, I.; SILVEIRA, P.R.S. et al. Suinocultura intensiva: Produção, manejo e saúde do rebanho. Brasília: Embrapa/SPI, 1998. p.45-60.

ROSTAGNO, H.S.; ALBINO, L.F.T.; DONZELE, J. et al. Tabelas brasileiras para aves e suínos: Composição de alimentos e exigências nutricionais. Viçosa: UFV, 2005. $141 \mathrm{p}$. 
SANTOS FILHO, J.I.; PINHEIRO, A.A.C.; BERTOL, T.M. et al. Avanço tecnológico $e$ alteração no peso ótimo de abate de suínos. Concórdia: Embrapa/CNPSA, 2001. Disponível em:

$<$ http://www.cnpsa.embrapa.br/sgc/sgc artigos/a rtigos_o8t704c.html/>. Acessado em: 29 abr. 2008.

SILVA, A.M.R.; BERTO, D.A.; LIMA, G.J.M.M. et al. Valor nutricional e viabilidade econômica de rações suplementadas com maltodextrina e acidificante para leitões desmamados. Rev. Bras. Zootec., v.37, p.286295,2008

SILVA, H.G.O.; PIRES, A.J.V.; SILVA, F.F. et al. Características físico-químicas e custo do leite de cabras alimentadas com farelo de cacau ou torta de dendê. Arq. Bras. Med. Vet. Zootec., v.58, p.116-123, 2006.

SUBPRODUTOS da laranja. São Paulo: Associação Brasileira de Exportadores Cítricos, $2006 . \quad$ Disponível em: $<$ http://www.abecitrus.com.br/subprodutos br.ht ml\#oessenciais/>. Acessado em: 18 out. 2006.

VIOLA, E.S.V.; CAZARRÉ, M.M.; DORNELES, R.A. et al. Efeito da restrição alimentar sobre o peso de órgãos e gordura da carcaça de camundongos (Mus musculus) em crescimento. In: REUNIÃO ANUAL DA SOCIEDADE BRASILEIRA DE ZOOTECNIA, 33., 1998, Botucatu. Anais... Botucatu: SBZ, 1998. p.244-247. 